Bull. Chem. Soc. Ethiop. 2013, 27(3), 413-419.

Printed in Ethiopia

ISSN 1011-3924

DOI: http://dx.doi.org/10.4314/bcse.v27i3.10

(C) 2013 Chemical Society of Ethiopia

\title{
SYNTHESIS AND CHARACTERIZATION OF NEW HEAT RESISTANCE AND ORGANOSOLUBLE POLY(ETHER-AMIDE)
}

\author{
Meisam Shabanian* and Nemat Basaki \\ Department of Chemistry, Farahan Branch, Islamic Azad University, Farahan, Iran
}

(Received September 25, 2012; revised March 16, 2013)

\begin{abstract}
New series of olefinic poly(ether-amide)s (OPEA)s 6a-f was synthesized from 4,4'-bis(1,4diphenoxybutane)diacrylic acid $\mathbf{4}$ and aromatic diamine $\mathbf{5 a - f}$ via a direct polycondensation reaction. The resulting polymers were characterized by Fourier transform infrared spectra (FTIR), nuclear magnetic resonance $\left({ }^{1} \mathrm{H}-\right.$ NMR), solubility test and inherent viscosity. The thermal properties of the polymers 6 a-c were investigated by thermogravimetric analysis (TGA). Polymer 6c due to presence of $\mathrm{SO}_{2}$ group as a polar group shows better thermal properties compare with polymer $\mathbf{6 a}$ and $\mathbf{6 b}$.
\end{abstract}

KEY WORDS: Polycondensation, Polyamide, Ether group, Thermal properties

\section{INTRODUCTION}

Aromatic polyamides are noted for high transparency, excellent mechanical properties, heat resistance, good char yield, low flammability, good barrier properties, and outstanding strengthto-weight ratios and solvent resistance [1-4]; however, they are difficult to process because of limited solubility and high glass transition $\left(\mathrm{T}_{\mathrm{g}}\right)$ [5-7]. The processing of these polymers has been greatly hindered because they lack softening or melting property at usual processing temperature, and they tend to decompose at the softening temperature. Many efforts have been made to create structurally modified aromatic polyamides having better solubility and processability. It is known that the solubility of polyamides is often increased when flexible bonds such as $\left[-\mathrm{CH}_{2^{-}},-\mathrm{O}-,-\mathrm{SO}_{2^{-}},-\mathrm{C}\left(\mathrm{CF}_{3}\right)_{2}\right]$, bulky pendent groups, polar components or large pendent groups are incorporated into the polymer backbone due to the altering crystallinity and intermolecular interactions [8-13], synthesis of polyamides with noncoplaner unit in the polymer chains [14], preparation of copolymers such as poly(amide-imide)s [15-18], poly(esterimide)s [19], poly(amide-ester-imide)s [20] and the introduction of bulky side groups into the polymer chains [21-23] resulted a series of modified polyamides.

It has been recognized that the incorporation of aryl-ether linkages generally imparts an enhanced solubility, processability, and toughness of aromatic polyamides without substantial diminution of thermal properties [24]. Aromatic polymers that contain aryl ether linkages generally have lower glass transition temperatures, greater chain flexibility, and tractability in compared to their corresponding polymers without these groups in the chain [25-27]. The lower glass transition temperatures and also improved solubility are attributed to the flexible linkages that provide a polymer chain with a lower energy of internal rotation [28].

In this article, new series of olefinic poly(ether-amide)s $6 \mathbf{a}-\mathbf{f}$ were synthesized by reacting 4,4'-bis(1,4-diphenoxybutane) diacrylic acid $\mathbf{4}$ and various diamine 5a-f via a direct polycondensation reaction in a medium consisting of $\mathrm{N}$-methyl-2-pyrrolidone, triphenyl phosphite, calcium chloride and pyridine.

\section{EXPERIMENTAL}

Materials

All chemicals were purchased from Fluka Chemical Co. (Switzerland), Aldrich Chemical Co. (Milwaukee, USA), Merck Chemical Co. (Germany) and Acros Organics NV/SA (Belgium).

*Corresponding author. E-mail: shabanian.m44@gmail.com 
Techniques

The Fourier transform infrared spectra (FTIR) were measured using the Bruker Vertex $80 \mathrm{~V}$ spectrometer over the wavenumber range of $600-4000 \mathrm{~cm}^{-1}$. NMR measurements were performed with a Bruker $300 \mathrm{MHz}$ and Bruker $500 \mathrm{MHz}$ spectrometer. DMSO- $\mathrm{d}_{6}$ was used as the solvent and the solvent signal was used for internal calibration (DMSO- $\mathrm{d}_{6}: \delta\left({ }^{13} \mathrm{C}\right)=39.6$ ppm, $\left.\delta\left({ }^{1} \mathrm{H}\right)=2.5 \mathrm{ppm}\right)$. Inherent viscosities were measured by a standard procedure by using a Technico Regd Trad Mark Viscometer. Thermal gravimetric analysis (TGA) data for the polymers were taken on a Mettler TA4000 System in the range between room temperature and $800{ }^{\circ} \mathrm{C}$ at a heating rate of $10^{\circ} \mathrm{C} / \mathrm{min}$ in nitrogen atmosphere.

\section{Monomer synthesis}

Synthesis of 4,4'-bis(1,4-diphenoxybutane) diacrylic acid 4. At first 4,4'-bis(1,4diphenoxybutane) dialdehyde $\mathbf{3}$ was synthesized from the reaction of 4-hydroxybenzaldehyde (34 mmol) 1 and $17 \mathrm{mmol}$ of dry $\mathrm{K}_{2} \mathrm{CO}_{3}$ in $30 \mathrm{~mL}$ dimethyl formamide (DMF) with $17 \mathrm{mmol}$ of 1,4-dibromo butane 2 in $5 \mathrm{~mL}$ dry dimethyl formamide. The reaction mixture was heated for $6 \mathrm{~h}$ at $120{ }^{\circ} \mathrm{C}$, then was cooled and poured onto crushed ice. The solid was precipitated, washed with the cold water and filtered at room temperature until product was obtained. ${ }^{1} \mathrm{H}-\mathrm{NMR}$ $\left(\right.$ DMSO-d $_{6}$, TMS) $\delta: 1.9(\mathrm{~s}, 4 \mathrm{H}), 4.11-5.15(\mathrm{~d}, 4 \mathrm{H}), 7.10-7.13(\mathrm{~d}, 4 \mathrm{H}), 7.84-7.87(\mathrm{~d}, 4 \mathrm{H}), 9.86$ (s, 2H) ppm. Then $5 \mathrm{mmol}$ of 4,4'-bis(1,4-diphenoxybutane) dialdehyde 3 were placed in a 100 $\mathrm{mL}$ beaker with $11 \mathrm{mmol}$ malonic acid using $1 \mathrm{~mL}$ morpholine under solvent-free conditions. The mixture compounds were heated until completely melted. Then the heating was removed and $20 \mathrm{~mL}$ of $5 \% \mathrm{HCl}$ was added in the reaction mixture slowly with stirring and the stirring continued at room temperature for $2 \mathrm{~h}$. After that the white precipitate was filtered and washed with $20 \mathrm{~mL} \mathrm{H}_{2} \mathrm{O}$ and filtered until white product was obtained. M.p. 323-325 ${ }^{\circ} \mathrm{C}$, FTIR $(\mathrm{KBr})$ : 2400-3500 (s, br), 1688 (s), 1627 (s), 1602 (s), 1510 (s), 1429 (s), 1310 (s), 1219 (s), 1171 (m), $1018(\mathrm{~s}, \mathrm{br}), 827(\mathrm{~m}), 680(\mathrm{~m}), 510(\mathrm{w}) \mathrm{cm}^{-1} .{ }^{1} \mathrm{H}-\mathrm{NMR}$ (DMSO-d 6 , TMS) $\delta: 1.87(\mathrm{~s}, 4 \mathrm{H}), 4.08$ $(\mathrm{s}, 4 \mathrm{H}), 6.34-6.40(\mathrm{~d}, 2 \mathrm{H}), 6.98-7.11(\mathrm{~d}, 4 \mathrm{H}), 7.51-7.57(\mathrm{~d}, 2 \mathrm{H}), 7.62-7.86(\mathrm{~d}, 4 \mathrm{H}), 12.36$ (s, br, 2H) ppm. ${ }^{13} \mathrm{C}-\mathrm{NMR}\left(\mathrm{DMSO}_{6}\right) \delta$ : 168.32, 160.77, 144.23, 130.42, 127.19, 115.87, 115.25, $67.73,25.73 \mathrm{ppm}$.

\section{Synthesis of olefinic poly(ether-amide)s}

Polyamides 6a-f were synthesized by direct polycondensation reaction. As an example the preparation of OPEA $6 \mathbf{e}$ is described below. OPEA $\mathbf{6 e}$ was prepared from the reaction of 4,4'bis(1,4-diphenoxybutane) diacrylic acid 4 with 4,4'-diaminodiphenyl-ether 5e. In a $25 \mathrm{~mL}$ round-bottomed flask which was fitted with a stirring bar were placed diacid 4 (0.64 mmol), 4,4'-diaminodiphenylether 5e $(0.64 \mathrm{mmol})$, calcium chloride $(0.20 \mathrm{~g}, 1.80 \mathrm{mmol})$, triphenyl phosphite $(1.68 \mathrm{~mL}, 6.00 \mathrm{mmol})$, pyridine $(0.36 \mathrm{~mL})$ and $\mathrm{N}$-methyl-2-pyrrolidone $(2 \mathrm{~mL})$. The reaction mixture was heated under reflux on an oil bath at $60^{\circ} \mathrm{C}$ for $1 \mathrm{~h}$, then $90^{\circ} \mathrm{C}$ for $2 \mathrm{~h}$, and $120{ }^{\circ} \mathrm{C}$ for $6 \mathrm{~h}$. The OPEA $6 \mathrm{e}$ formed was viscous, then the reaction mixture was poured into 50 $\mathrm{mL}$ of methanol and the precipitated polymer was collected by filtration and washed thoroughly with hot methanol and dried at $60{ }^{\circ} \mathrm{C}$ for $12 \mathrm{~h}$ under vacuum to leave solid OPEA $6 \mathrm{e}$.

Polymer 6a. FTIR (KBr): 3320 (m), 2947 (m), 1689 (s), 1589 (m), 1541 (m), 1481 (m), 1384 (m), $1186(\mathrm{~m}), 690(\mathrm{w}), 501(\mathrm{w}) \mathrm{cm}^{-1}$.

Polymer 6b. FTIR (KBr): 3310 (w), 3075 (m), 2957 (m), 1685 (s), 1622 (s), 1578 (m), 1539 (m), $1480(\mathrm{~m}), 1424(\mathrm{~m}), 1380(\mathrm{~m}), 1278(\mathrm{~m}), 1170(\mathrm{~m}), 1079(\mathrm{~m}), 950(\mathrm{w}), 729(\mathrm{~m}), 699(\mathrm{~m})$ $\mathrm{cm}^{-1}$. 
Polymer 6c. FTIR (KBr): 3328 (w), 3032 (m), 2960 (m), 1688 (s), 1615(s), 1522 (m), 1540 (m), $1483(\mathrm{~m}), 1427(\mathrm{~m}), 1380(\mathrm{~m}), 1308(\mathrm{~m}), 1180(\mathrm{~m}), 1071(\mathrm{~m}), 962(\mathrm{w}), 727(\mathrm{~m}), 650(\mathrm{~m}) \mathrm{cm}^{-1}$.

Polymer 6d. FTIR (KBr): 3287 (w), 3025 (m), 2955 (m), 1670(s), 1550 (m), 1481 (m), 1435 (m), $1385(\mathrm{~m}), 1310(\mathrm{~m}), 1165(\mathrm{~m}), 1064(\mathrm{~m}), 952(\mathrm{w}), 730(\mathrm{~m}), 652(\mathrm{~m}) \mathrm{cm}^{-1}$.

Polymer 6e. FTIR (KBr): 3267 (w), 3020 (m), 2945 (m), 1669 (s), 1549 (m), 1479 (m), 1435 (m), $1388(\mathrm{~m}), 1268(\mathrm{~m}), 1165(\mathrm{~m}), 1062(\mathrm{~m}), 952(\mathrm{w}), 731(\mathrm{~m}), 655(\mathrm{~m}) \mathrm{cm}^{-1}$.

Polymer 6f. FTIR (KBr): 3332 (w), 3018 (m), 2975 (m), 1684 (s), 1549 (m), 1479 (m), 1435 (m), $1388(\mathrm{~m}), 1259(\mathrm{~m}), 1165(\mathrm{~m}), 1068(\mathrm{~m}), 952(\mathrm{w}), 726(\mathrm{~m}), 651(\mathrm{~m}) \mathrm{cm}^{-1}$.

\section{RESULTS AND DISCUSSION}

\section{Monomer synthesis}

Dicarboxylic acid $\mathbf{4}$ containing aryl ether and methylene group was synthesized by using two step reactions. At first 4,4'-bis(1,4-diphenoxybutane)dialdehyde 3 was prepared from the reaction of one equimolar 1,4-dibromobutane $\mathbf{2}$ and two equimolars 4-hydroxybenzaldehyde $\mathbf{1}$. Then dialdehyde compound $\mathbf{3}$ was reacted with malonic acid at presence of catalytic amount of morpholine under a solvent free condition. The chemical structure and purity of dicarboxylic acid compound $\mathbf{4}$ were confirmed by FTIR, ${ }^{1} \mathrm{H}-\mathrm{NMR}$, and ${ }^{13} \mathrm{C}-\mathrm{NMR}$ spectroscopy.

Polymer synthesis

Olefinic poly(ether-amide)s 6a-f were synthesized via direct polycondensation reaction of diacid 4 with aromatic diamine $\mathbf{5 a - f}$ via direct polycondensation reaction in a medium consisting of $\mathrm{N}$ methyl-2-pyrrolidone (NMP), triphenyl phosphite (TPP), calcium chloride and pyridine (Scheme 1). The OPEAs 6a-f were obtained in good yields (Table 1).

Table 1. Some physical properties of OPEAs 6a-f.

\begin{tabular}{|c|c|c|c|}
\hline Polymer & Yield $(\%)$ & $\eta_{\text {inh }}(\mathrm{dL} / \mathrm{g})^{\mathrm{a}}$ & Color $^{\mathrm{b}}$ \\
\hline $\mathbf{6 a}$ & 93 & 0.72 & $\mathrm{Y}$ \\
\hline $\mathbf{6 b}$ & 96 & 0.66 & $\mathrm{Y}$ \\
\hline 6c & 95 & 0.67 & $\mathrm{C}$ \\
\hline 6d & 91 & 0.61 & $\mathrm{C}$ \\
\hline 6e & 94 & 0.58 & $\mathrm{Y}$ \\
\hline 6f & 89 & 0.57 & $\mathrm{~B}$ \\
\hline
\end{tabular}

${ }^{\mathrm{a}}$ Measured at a concentration of $0.5 \mathrm{~g} / \mathrm{dL}$ in $\mathrm{DMF}$ at $25^{\circ} \mathrm{C} .{ }^{\mathrm{b}} \mathrm{B}=$ Brown, $\mathrm{C}=$ Cream, $\mathrm{Y}=$ Yellow.

\section{Polymer characterization}

The structure of polymer was confirmed by ${ }^{1} \mathrm{H}-\mathrm{NMR}$ and FTIR spectroscopies. FTIR data of OPEAs 6a-f exhibited characteristic absorption bands around $1670 \mathrm{~cm}^{-1}$ for the amide group $(\mathrm{C}=\mathrm{O}$ stretching vibration) and the $\mathrm{N}-\mathrm{H}$ stretching absorption bands of amide groups around $3280 \mathrm{~cm}^{-1}$ (N-H stretching). The ${ }^{1} \mathrm{H}-\mathrm{NMR}$ spectrum of polymer $\mathbf{6 e}$ showed peaks that confirm its chemical structure (Figure 1). The aromatic and olefinic protons related to polymer backbone appeared in the region of 6.6-7.8 ppm. The protons related to methylene group appeared at 1.9 and $4.1 \mathrm{ppm}$ and the peak in the region of $10.5 \mathrm{ppm}$ is assigned for $\mathrm{NH}$ of the amide groups in the polymer chain. 

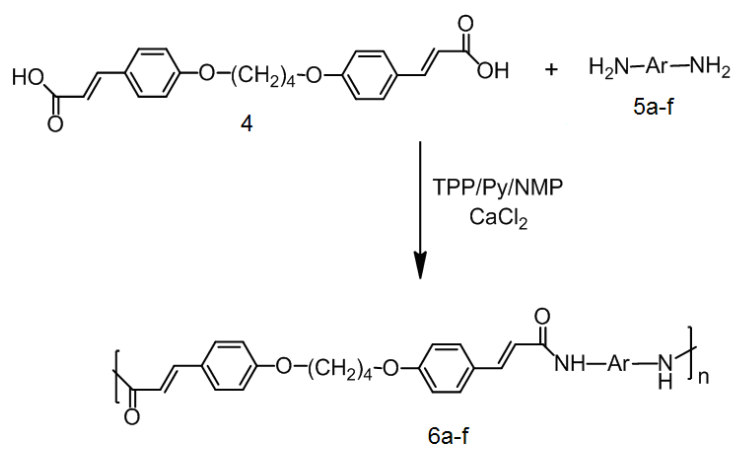

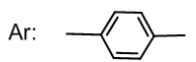

$5 a$

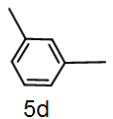

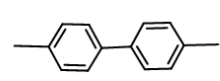

$5 b$

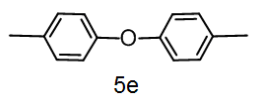

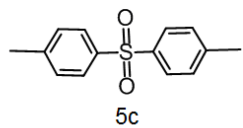

$5 c$

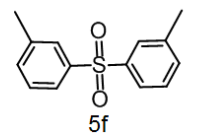

Scheme 1. Synthesis route of olefinic poly(ether-amide) 6a-f.

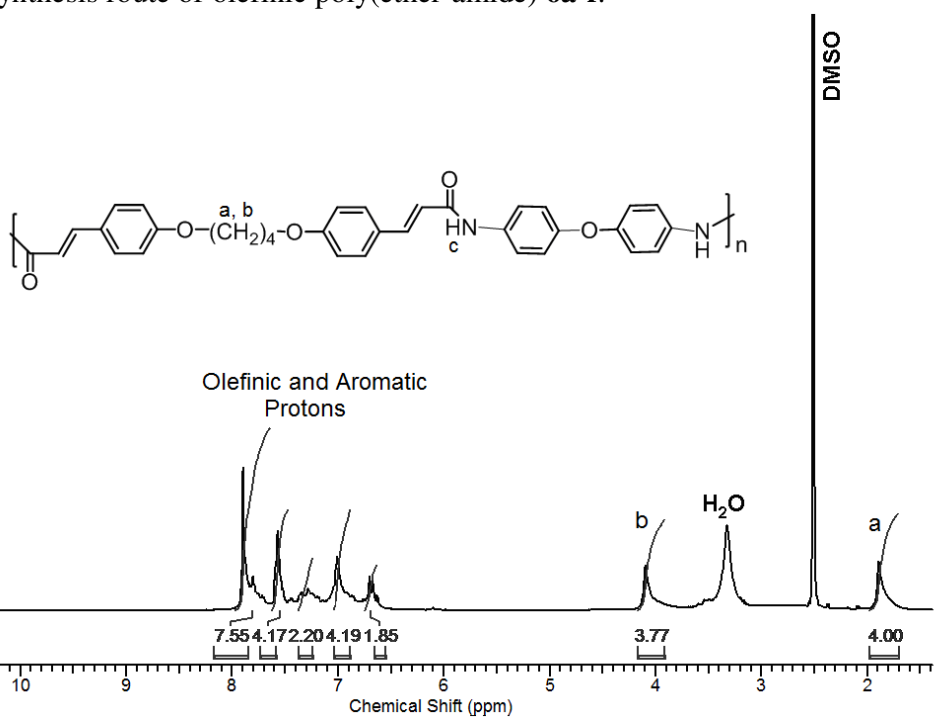

Figure 1. ${ }^{1} \mathrm{H}-\mathrm{NMR}$ spectrum of OPEA $\mathbf{6 e}$.

\section{Solubility test}

One of the main objectives of this study was producing modified polyamides with improved solubility. The incorporation of monomers with flexible group such as ether moieties in the polymer backbone, led to these polymers have good solubility in various solvents, especially organic aprotic solvents. The solubility of OPEAs 6a-f was investigated as $0.01 \mathrm{~g}$ of polymeric

Bull. Chem. Soc. Ethiop. 2013, 27(3) 
sample in $2 \mathrm{~mL}$ of solvent. Remarkably, all of OPEAs were easily soluble at room temperature in aprotic polar solvents such as N-methyl-2-pyrrolidone (NMP), N,N-dimethylacetamide (DMAc), N,N-dimethylformamide (DMF) and insoluble in solvents such as acetone, chloroform, ethanol and methanol (Table 2).

Table 2. Solubility of OPEAs 6a-f.

\begin{tabular}{|c|c|c|c|c|c|c|}
\hline Solvent & $\mathbf{6 a}$ & $\mathbf{6 b}$ & $\mathbf{6 c}$ & $\mathbf{6 d}$ & $\mathbf{6 e}$ & $\mathbf{6} \mathbf{0}$ \\
\hline DMAc & + & + & + & + & + & + \\
\hline DMSO & + & + & + & + & + & + \\
\hline DMF & + & + & + & + & + & + \\
\hline NMP & + & + & + & + & + & + \\
\hline Cyclohexanone & - & - & - & - & - & - \\
\hline $\mathrm{CHCl}_{3}$ & - & - & - & - & - & - \\
\hline Acetone & - & - & - & - & - & - \\
\hline EtOH & - & - & - & - & - & - \\
\hline $\mathrm{MeOH}$ & - & - & - & - & - & - \\
\hline $\mathrm{H}_{2} \mathrm{O}$ & - & - & - & - & - & - \\
\hline
\end{tabular}

Solubility: + : soluble; -: insoluble.

\section{Thermal properties}

Thermal stability of the OPEA 6a-c determined under inert atmosphere is shown in Figure 2. The initial decomposition temperatures of $5 \%$ and $10 \%$ weight losses $\left(\mathrm{T}_{5}\right.$ and $\left.\mathrm{T}_{10}\right)$ and the char yield at $800{ }^{\circ} \mathrm{C}$ are summarized in Table 3 . Thermal decomposition temperatures of the polymers were found in the range $237-241{ }^{\circ} \mathrm{C}$. Compared with the thermal decomposition behavior of OPEA 6a, OPEA $\mathbf{6 b}$ and $\mathbf{6 c}$ with two benzene rings show higher $5 \mathrm{wt} \%$ and $10 \mathrm{wt} \%$ and delay the decomposition. The weight retained at $800{ }^{\circ} \mathrm{C}$ shows higher char residue at high temperature and improves significantly with percent of $\mathrm{SO}_{2}$ group.

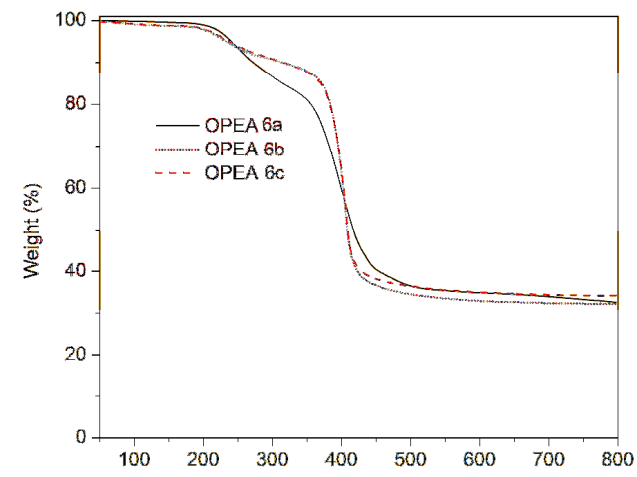

Figure 2. TGA curves of OPEAs 6a-c.

Table 3. Thermal and fire measurements of OPEAs 6a-c.

\begin{tabular}{|c|c|c|c|}
\hline Polymer & $\mathrm{T}_{5}\left({ }^{\circ} \mathrm{C}\right)^{\mathrm{a}}$ & $\mathrm{T}_{10}\left({ }^{\circ} \mathrm{C}\right)^{\mathrm{a}}$ & Char yield $^{\mathrm{b}}$ \\
\hline OPEA 6a & 241 & 273 & 33.34 \\
\hline OPEA 6b & 234 & 315 & 33.10 \\
\hline OPEA 6c & 237 & 316 & 34.96 \\
\hline
\end{tabular}

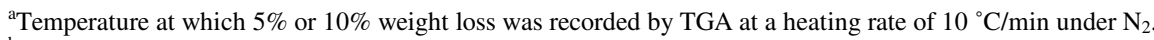
${ }^{b}$ Weight percentage of material left after TGA analysis at a maximum temperature of $800{ }^{\circ} \mathrm{C}$. 


\section{CONCLUSIONS}

In this article, an efficient method for the synthesis of 4,4'-bis(1,4-diphenoxybutane) diacrylic acid 4, containing ether and olefinic groups, has been developed under solvent free condition in presence of morpholine as a catalyst. New poly(ether-amide)s with good inherent viscosity were prepared by the direct polycondensation reaction of the synthesized diacid and aromatic diamine 5a-f. The results presented herein also clearly demonstrate that incorporating the ether group into the polymer main chain as well as combination of the wholly aromatic backbone and several functional groups remarkably enhanced the solubility in organic solvents of the new polymers. The thermal stability and char residue of the OPEA $6 \mathbf{c}$ due to presence $\mathrm{SO}_{2}$ have been increased as compared with the OPEA 6a. These properties could make these OPEAs attractive

for practical applications such as processable high-performance engineering plastics.

\section{ACKNOWLEDGEMENTS}

The authors wish to acknowledge the support of this work by the research council of Farahan branch, Islamic Azad University, Farahan, Iran.

\section{REFERENCES}

1. Hsiao, S.H.; Chang, Y.H. Eur. Polym. J. 2004, 40, 1749.

2. Chatfield, D.A.; Einhorn, I.N.; Mickelson, R.W.; Futrell, J.H. J. Polym. Sci. Part A: Polym. Chem. 1979, 17, 1353.

3. Faghihi, K.; Shabanian, M. Macromol. Res. 2010, 18, 1148.

4. Zulfiqar, S.; Ahmad, Z.; Ishaq, M.; Sarwar, M. I. Mat. Sci. Eng. A. 2009, 525, 30.

5. Sarwar, M.I.; Zulfiqar, S.; Ahmad Z. Polym. Int. 2008, 57, 292.

6. Shabanian, M.; Faghihi, K.; Shabani, F. Polym. Bull. 2012, 68, 375.

7. Liou, G.S.; Lin, H.Y.; Yen, H.J. J. Mater. Chem. 2009, 19, 7666.

8. Faghihi, K.; Hajibeygi, M.; Shabanian, M. J. Macromol. Sci. Part A: Pure Appl. Chem. 2010, 47, 44.

9. Diakoumakos, C.D.; Mikroyannidis, J.A. Polymer. 1994, 35, 1986.

10. Faghihi, K.; Shabanian, M. J. Thermoplast. Compos. Mater. 2012, 25, 89.

11. Faghihi, K.; Shabanian, M.; Emamdadi, N. Macromol. Res. 2010, 18, 753.

12. Faghihi, K.; Shabanian, M.; Izadkhah, A. Chinese J. Polym. Sci. 2010, $28,589$.

13. Mllakpour, S.; Kowsari, E. Polym. Adv. Technol. 2005, 16, 732.

14. Liaw, D.J.; Hsu, P.N.; Liaw, B.Y. J. Polym. Sci. Part A: Polym. Chem. 2001, 39, 63.

15. Hajibeygi, M.; Shabanian M.; Khodaei-Tehrani, M. Des. Monomers Polym. 2011, 14, 617.

16. Ghaemy, M.; Khajeh, S. Chinese J. Polym. Sci. 2012, 30, 82.

17. Mansoori, Y.; Shah Sanaei, S.; V. Atghia, S.; Zamanloo M.R.; Gh. Imanzadeh. Chinese J. Polym. Sci. 2011, 29, 699.

18. Hajibeygi, M.; Faghihi, K.; Shabanian, M. J. Appl. Polym. Sci. 2011, 121, 2877.

19. Patel, H.S.; Patel, B.P.; Patel, D.B. Int. J. Polym. Mater. 2009, 58, 625.

20. Liaw, D.J.; Liaw, B.Y.; Yang, C.M. Macromol. Chem. Phys. 2001, 202, 1866.

21. Ayala, V.; Maya, E.M.; Garcia, J.M.; de la Campa, J.G.; Lozano, A.E.; Abajo, J. J. Polym. Sci. Part A: Polym. Chem. 2005, 43, 112.

22. Hsiao, S.H.; Yang, C.P.; Chen, C.W.; Liou, G.S. Eur. Polym. J. 2005, 41, 511.

23. Sava, I.; Bruma, M. Macromol. Symp. 2006, 239, 36.

24. Hajibeygi, M.; Shabanian, M. J. Appl. Polym. Sci. 2012, 126, 280. 
25. Hale, W.F.; Farnham, A.G.; Johnson, R.N.; Clendinning, R.A. J. Polym. Sci. Part A: Polym. Chem. 1976, 5, 2399.

26. Johnson, R.N.; Farnham, A.G.; Clendinning, R.A.; Hale, W.F.; Merriman, C.N. J. Polym. Sci. Part A: Polym. Chem. 1967, 5, 2375.

27. Faghihi, K.; Hajibeygi, M. Chinese J. Polym. Sci. 2010, 28, 517.

28. Gutch, P.K.; Banerjee, S.; Jaiswal, D.K. J. Appl. Polym. Sci. 2003, 89, 691. 